\title{
BREAST CANCER PATIENTS;
}

\author{
Identification of mutation(s) in BRCA1 gene
}

Dr. Muhammad Fiaz Qamar, Miss Farah Rehman, Miss Sabeen llyas, Miss Seher Abbas

ABSTRACT... Objective: Genetic factors contribute to the high rates with breast cancer patients. Our objective was to screen the mutations in the BRCA 1 gene in exon 20. Design: A diagnostic study. Place and Duration of Study: The study was carried out in molecular biology lab, Department of Zoology, GC University Lahore and Institute of Molecular Biology and Biotechnology (IMBB), University of Lahore over a period of one year from July 2011 to Aug 2012. Patients and Methods: To screen for mutation in the BRCA1 gene, blood samples were collected from 22 different patients suffering from breast cancer from the Anmol Hospital and Sir Ganga Ram Hospital Lahore. The collected samples were processed to screen any mutation in exon 20 which is indicative of the fact that exon 20 is not a hotspot for mutations. Results: In our study of 22 females, we have found no mutation in the gene. It is becoming increasingly clear that breast cancer is a multifaceted and heterogeneous disease and histopathological characteristics of breast cancer are controlled by subsets of genetic alterations, providing convincing hints of genotypic-phenotypic correlations between morphological patterns and molecular changes. BRCA has emerged as the master regulator of the genome through its ability to regulate and coordinate various steps of DNA damage response. Women who carry a mutation of the gene have greatly increased chance of developing breast cancer. The population of Pakistan has been substantially screened for somatic and germline mutations in BRCA. Conclusions: Breast cancer is the most common cancer of women in Pakistan. One every 8th women is found to carry the disease. A female may develop the disease through inherited mutations in the BRCA1 gene. The absence of mutation maybe attributed to small sample size of the study or may be due to the fact that the size of the gene is so large that a single axon may not be enough to screen for mutations.

Key words: Breast Cancer; Gene BRCA1; Pakistan; Risk Factors.

Article Citation

Qamar MF, Rehman F, Ilyas S, Abbas S. Breast cancer patients; identification of mutation (S) in Brca 1 gene. Professional Med J 2013;20(6): 1019-1025.

\section{INTRODUCTION}

Breast cancer $(\mathrm{BC})$ is reported to be the most common type of cancer and involves approximately one third of malignancies in the females worldwide and is responsible for approximately one quarter of cancer related deaths in females ${ }^{1}$. Young females (less than age 35) are reported to have more aggressive form of disease than the older ones (less than age 75) thereby causing a higher mortality rate in the former case ${ }^{2}$. Approximately ninety-five percent of breast carcinomas arise from breast epithelial elements. Invasive (infiltrating) breast cancers spread outside the membrane that lines a duct or lobule, invading the surrounding tissues. The cancer cells can then travel to other parts of the body, such as the lymph nodes ${ }^{1}$.

Different risk factors associated with the increased incidence of breast cancer include gender (females have a higher rate of incidence than men), hormonal history (cumulative exposure to estrogen and progesterone), hormone replacement therapy, cousin marriages, tobacco, excess alcohol consumption, obesity, excessive sunlight exposure, diet, physical activity, environmental toxins, certain types of infections and environmental exposure to different chemicals and radiations ${ }^{3}$. Hereditary breast cancer cases account for about 5-10\% while $90-95 \%$ of other breast cancer cases are sporadic ${ }^{4}$. Genetic mutations in Breast Cancer Anti-estrogen resistance-1 genes (BRCA1), Breast Cancer Anti-estrogen resistance-2 gene (BRCA2), Ataxia Telangiectasia mutant gene (ATM), Phosphate and Tensin homology (PTEN) and Tumor suppressor Protein (P53) and several genes are also involved in the onset of $\mathrm{BC}^{5,7}$. Approximately $80 \%$ of the cases of hereditary breast cancer are due to mutations in either BRCA1 (40-45\%) or BRCA2 (35$40 \%)$. Mutations in the various genes are associated with the some of the remaining $20 \%$ of cases: e.g., 
Cowden syndrome (the PTEN tumor suppressor), LiFraumeni syndrome (p53), and the androgen receptor.

BRCA1 gene is located on the $q$ arm of chromosome 17 and at band 21. BRCA1 gene is a very huge gene that spread over almost $100 \mathrm{~kb}$ of total genomic DNA. The gene consists of 24 exon among which 1 and 4 are non-coding and are not analyzed, and codes for a protein of 1863 amino acids which produces a nuclear protein of about $220 \mathrm{kd}^{9}$. The gene is mainly involved in the maintenance of genomic stability as well as functions as tumor suppressor gene. However any transformation in the gene results in serious malfunctioning; thus leading to breast cancer development ${ }^{4}$. Normally BRCA1 gene repairs a broken PTEN gene by sewing it back together. When BRCA 1 is mutated, it stops repairing PTEN gene, hence contributing towards development of cancer and metastasis.

No repair of PTEN gene by BRCA1 results in cell growth, proliferation, cell death inhibition, cell migration, new blood vessels sprout and metastasis. Mutations in the BRCA1/2 gene are found in most families with a positive history of breast cancer or with many cases of early onset breast cancer, especially if they also include one or more patients with ovarian cancer $^{3}$. However, BRCA1 somatic mutations have seldom been reported in sporadic breast cancer ${ }^{10}$. There are more than 600 different mutations that have been identified in BRCA1 gene and 450 mutations in $B R C A 2^{11}$. Mutation of BRCA1 is thought to account for approximately $45 \%$ of families with significantly high breast cancer incidence and at least $80 \%$ of families with increased incidence of both early-onset breast cancer and ovarian cancer ${ }^{12}$. It has been recognized for several years that BRCA1 related breast cancers are more likely to be estrogen receptor (ER) negative ${ }^{13}$. Women diagnosed with high-grade, estrogen receptor negative breast cancer before the age of 30 years have a $40-45 \%$ chance of harboring a BRCA1 mutation, compared with a $4-5 \%$ chance if these parameters are notmet ${ }^{13}$.

There are many genetic tests for BRCA1 and BRCA 2 mutations but techniques based on sequencing and denaturing high performance liquid chromatography, denaturing gradient gel electrophoresis offer the greatest accuracy; but these techniques are expensive. The breast cancer screening recommendations are based on data from families with cancer predisposing BRCA1 mutations, which shows that elevated breast cancer risk begins in the late 20 s or early 30 s. Screening should be started with monthly breast self-examination in early adulthood, annual clinical examination at age 25-35 years and annual mammography at age 25-35 years ${ }^{14}$.

Mammography, ultrasound and magnetic resonance imaging (MRI) are usually recommended for the diagnosis of disease. Surgery may also be done to remove the 'at risk' tissues ${ }^{15}$.

Chemoprevention is also used to reduce the risk of developing breast cancer or to reduce the risk of regetting the cancer. For example, the drug tamoxifen has been proved effective in the treatment of diagnosed breast cancer as well as to lower the risk of breast cancer in BRCA1 mutation carriers. Tamoxifen appears to be effective in reducing both local recurrence and contralateral breast cancer in women with BRCA1 mutations ${ }^{8}$.

At present, in Pakistan breast cancer is the most common type of cancer occurring in women, followed by the cancer of oral cavity and the ovary ${ }^{16}$. In Asia, Pakistan has one of the highest rates of breast cancer, and majority of the cases occur below age $40^{16,17}$. Only one study from Pakistan has described relationship between consanguinity and the risk of breast cancer ${ }^{18}$. The objective of this study was to find association/linkage of BRCA1 gene in breast cancer patients. The mutations in Breast Cancer Susceptibility 
(BRCA1) gene in exon 20 in Pakistani breast cancer females were studied.

\section{MATERIALS AND METHODS}

To screen for mutation in the BRCA1 gene, blood samples were collected from different patients suffering from breast cancer. The sampling was done from the Anmol Hospital and Sir Ganga Ram Hospital Lahore. About $3 \mathrm{ml}$ of blood sample from each patient was collected in blood vacutainer EDTA tubes. The collected samples were stored at $-20^{\circ} \mathrm{C}$ in molecular biology lab, Department of Zoology, GC University

\begin{tabular}{|c|c|c|}
\hline Type of cancer & Age at diagnosis & Duration of cancer \\
\hline CA Breast & 35 years & 3 months \\
\hline CA Breast & 47 years & 1 year \\
\hline CA Breast & 31 years & 5-6 months \\
\hline CA Breast & 37 years & 2 year \\
\hline CA Breast & 40 years & 2 months \\
\hline CA Breast & 33 years & 3-4 months \\
\hline CA Breast & 35 years & 6 months \\
\hline CA Breast & 38 years & 5-6 months \\
\hline CA Breast & 45 years & 1 year \\
\hline CA Breast & 40 years & 1 year \\
\hline CA Breast & 38 years & 4 months \\
\hline CA Breast & 50 years & 3 months \\
\hline CA Breast & 42 years & 3 months \\
\hline CA Breast & 35 years & 6-7 months \\
\hline CA Breast & 49 years & 3 months \\
\hline CA Breast & 36 years & 4 months \\
\hline CA Breast & 44 years & 4 months \\
\hline CA Breast & 39 years & 8 months \\
\hline CA Breast & 33 years & 2 months \\
\hline CA Breast & 35 years & 6 months \\
\hline CA Breast & 31 years & 3 months \\
\hline CA Breast & 28 years & 5 months \\
\hline
\end{tabular}

Lahore and Institute of Molecular Biology and Biotechnology (IMBB), University of Lahore. History of patients is as follows:

\section{DNAEXTRACTION}

Blood obtained from the patients was subjected to DNA extraction to get genomic DNA. The modified phenol chloroform method was used to extract Genomic DNA ${ }^{19}$.

\section{GEL ELECTROPHORESIS}

Horizontal gel electrophoresis method was used for the confirmation of extracted DNA (John and Stowell, 2006).

\section{AMPLIFICATION OF GENE}

The amplification of gene was done by using the method as described by Chan et al., 2001².

\section{PRIMER DESIGNING}

To amplify the exons 20 , two sets of primers were designed from already reported sequence of BRCA1 gene $^{21}$. The sequences of designed primers are given below:

\begin{tabular}{|l|l|l|l|}
\hline $\begin{array}{c}\text { BRCA1 } \\
\text { gene }\end{array}$ & \multicolumn{1}{|c|}{ Exon } & $\begin{array}{c}\text { Primer sequence } \\
\left(\mathbf{5}^{\prime}-\mathbf{3}^{\prime}\right)\end{array}$ & \multicolumn{1}{|c|}{ Exon size } \\
\hline & E20F & $\begin{array}{c}5 \square \text { ATATGACGTG } \\
\text { TCTGCTCCAC3 } \square\end{array}$ & $401 \mathrm{bp}$ \\
\hline & E20R & $\begin{array}{l}5 \square \text { GGGAATCCAA } \\
\text { ATTACACAGC3 } \square\end{array}$ & $401 \mathrm{bp}$ \\
\hline
\end{tabular}

Table-II. Primer sequence.

\section{POLYMERASE CHAIN REACTION}

The gene was amplified by Polymerase Chain Reaction (PCR) with a final volume of $25 \mu$ l with thermocycling conditions as described by Dufresen et al., 2006 


\begin{tabular}{|l|}
\hline Cycling condition \\
\hline Initial denaturation at 97 for 4 min \\
\hline Followed by 40 cycles of denaturation at 94 for 1 min \\
\hline Annealing at 57 for 1 min, extension at 72 for 1.5 min \\
\hline Final extension at 72 for 8 min \\
\hline Table-III. PCR cycling condition \\
\hline
\end{tabular}

\section{AGAROSE GEL ELECTROPHORESIS OF PCR PRODUCT}

Amplification of specific gene fragments was confirmed by agarose gel electrophoresis. For this $3 \mu \mathrm{l}$ of 6X DNA loading dye was added to $5 \mu$ PCR product. Hundred milliliters $(100 \mathrm{ml})$ of $1 \%$ agarose gel was prepared in 1X TAE buffer (prepared from 50X TAE). Amplified products were loaded and the gel was run for 40 minutes at 90 volts. UV transilluminator was used to visualize the amplified product.

\section{GENE CLEAN AND DNA QUANTIFICATION}

To purify the amplified PCR fragment from the gel desired bands of PCR amplified products were cut from agarose gel by using a sterilized razor and saved in eppendorf tubes. Each fragment was weighed using digital electronic balance. Equal volume of Binding buffer (GB buffer) was added to the eppendorf having slice of amplified DNA and was incubated at $55^{\circ} \mathrm{C}$ for $10 \mathrm{~min}$ or until gel melted completely. Dissolved gel was transferred to the gene clean column and was centrifuged at 10000rpm for 1 minute. To remove the contamination $500 \mu \mathrm{l}$ of wash buffer were added to each column and centrifuged it for 1 minute at 10000rpm. Filtrate was discarded. This step was repeated again to ensure the removal of all contaminants. Empty column was dried by centrifuging at 10000rpm for 1 minute. The column was transferred to new labelled micro-centrifuge tube and $50 \mu$ l of elution buffer was added to the center of column membrane and allowed to stand for 2 minutes. Amplified DNA was collected in eppendorf tubes by centrifugation of columns at 10000rpm for 2 minutes. Purified PCR product was stored at $-20^{\circ} \mathrm{C}$.

After gene clean $5 \mu$ l of product was loaded on $1 \%$ agarose gel. Six microliters of DNA Ladder Mix were loaded for comparing the intensity of DNA bands.

\section{SEQUENCING}

About 30ng of each gene clean product was sent to CAMB (Center of Advanced Molecular Biology) for sequencing along with E20F and E20R primers. The sequencing results showed their homology with exon 20. Sequences were be further analyzed for mutations.

\section{SEQUENCING ANALYSIS}

Peaks of the sequences received from CAMB were analyzed carefully for their quality and then blasted in Nucleotide Blast of NCBI.

\section{RESULTS}

To look for mutations in BRCA1 gene blood samples were collected from Inmol Hospital Lahore and Sir Ganga Ram Hospital Lahore. About 3ml of blood was taken from the patients and transferred to EDTA vials. The samples were brought to Molecular Biology Lab of Zoology Department and Institute of Molecular and Biotechnology (IMBB) of University of Lahore and stored at $-20^{\circ} \mathrm{C}$.

\section{ISOLATION OF GENOMIC DNA}

The genomic DNA was isolated from blood samples of patients suffering from breast cancer using a modified phenol chloroform protocol. Sodium dodecyl sulphate (SDS) was used to lyse the WBCs and denature the proteins. Pretease $\mathrm{K}$ was used to lyse nuclear membrane. After isolation the genomic DNA was stored at $-20^{\circ} \mathrm{C}$. About $5 \mu \mathrm{l}$ of isolated genomic DNA along with $3 \mu \mathrm{l} 6 \mathrm{X}$ loading dye is loaded in wells on $1 \%$ agarose gel for electrophoresis. After 40 minutes the gel was visualized on UV trans-illuminator. Bright bands of DNA were observed at high molecular weight. 


\section{PCR RESULT OF BRCA1 GENE}

After primer designing exon 20 of BRCA1 gene was amplified using progene thermocycler. Different optimized conditions were used for the amplification of the exon. Optimized products were obtained by PCR at $50^{\circ} \mathrm{C}$ by using $0.64 \mathrm{mM}$ dNTPs and $2 \mathrm{mM} \mathrm{MgCl} 2$ in the presence of $1 \mathrm{X}$ Taq buffer with (NH4)2S04. The product was again loaded on $1 \%$ agarose gel for electrophoresis. Sharp bands of DNA were visualized at $401 \mathrm{bp}$. Following figures are showing the results of PCR amplification:

\section{RESULTS OF SEQUENCING}

The sequence obtained is homologous to normal human genome sequence. No mutation is observed in our case study of breast cancer patients.

\section{DISCUSSION}

Breast cancer is the most common malignancy of females affecting every one in eight women during their lifetime and about one million females are diagnosed with breast cancer every year ${ }^{524}$. The disease is more common and severe in young females than the older ones ${ }^{2}$. Most of the breast cancer cases reported today are sporadic and have no genetic lineage in their families. However, about $5 \%$ of cases have been considered hereditary and run in families through their genetic linkage. In Pakistan, breast carcinomas are the most common carcinomas among women with incidence rates similar to those reported in the west?. In Karachi, Pakistan the age standardized rates (ASR) of BC are reported to be $51.7 / 100,000$ per year, the highest ASR reported for any Asian population. In other Asian populations, these rates are reported to be $<40$ per100,000 per year ${ }^{6,16}$. Confluence of information suggested that BRCA1 acted as a scaffold in the assembly of a multiprotein complex and had functionalities in gene transcription, DNA damage repair and transcriptioncoupled DNA damage repair.

In different areas of Punjab, families have different rates of mutations, e.g; Punjabi families have 1128 cases of mutations (4184del4; axon20), 1071 have mutations (2041insA; axon 20). In Pashtun families (2080insA; axon20) mutations in 90 cases are found. At international level British families have one case of (ivs20+60 ins 12bp) in axon 20. Seven families have axon 20 deletions. Four cases have 5382inSC, which also occurs in axon 20. The major (non genetic) risk factors for breast and ovarian cancer are reproductive and dietary factors. Pakistani women have a low frequency of these traditional risk factors. The female population, on average, has high levels of fertility, early age at first pregnancy, multiple births, and prolonged breast-feeding. Although the age at first marriage has been gradually rising, women in consanguineous unions marry at earlier ages and are less likely to use modern contraceptive methods than are women from nonconsanguineous marriages ${ }^{23}$. Generally, Pakistani women do not use exogenous hormones (oral contraception or estrogen-replacement therapy). They generally do not smoke tobacco products, although some women practice chewing pan and pan tobacco. Furthermore, the population of Pakistan is predominantly Muslim (97\%), and alcohol consumption is uncommon ${ }^{7}$. Our study did not report any mutation in exon 20 of BRCA. It needs to be investigated in detail among breast cancer subtypes. Our sampling was random and we did not include data of the chemotherapeutic drugs. Moreover we did not evaluate BRCA mutations in breast cancer subtypes. Moreover, mutations in other regulators of DNA damage signaling and downstream effectors of cell signaling were not screened. The expression of BRCA in our study was not determined as there is a possibility of a transcriptional down regulation or miRNA mediated targeting of BRCA. All these aspects need detailed investigation.

\section{CONCLUSIONS}

Breast cancer is the most common cancer of women in Pakistan. One every 8th women is found to carry the disease. A female may develop the disease through 
inherited mutations in the BRCA1 gene. In our case study of 22 females, we have found no mutation in the gene. The absence of mutation maybe attributed to small sample size of the study or may be due to the fact that the size of the gene is so large that a single axon may not be enough to screen for mutations.

Copyright(c) 20 June 2013.

\section{REFERENCES}

1. Richie $C R$ and 0 J Swanson. Breast Cancer: A Review of the Literature. J Insur Med. 2003; 5:85-101.

2. Costanza M E. Epidemiology and risk factors for breast cancer. In: Up-to-date. 2001; 9:2-3.

3. Ford D, Easton D F, Bishop D T, Narod SA and Goldgar $D E$. Risks of cancer in BRCA1 mutation carriers. Breast Cancer Linkage Consortium. Lancet. 1994; 343:692-695.

4. Rosen M E, Fan S, Pestell G R, and Goldberg D I. BRCA1 Gene in Breast Cancer. Journal of Cellular Physiology 2003;196:19-41.

5. Gezeery E A, Mahmoud N, Moustafa A, Mahrous H, Mahmoud $H$, and Abd el- menam N. BRCA1 gene mutation in familial breast cancer. Turkish Journal of Cancer. 2008; 38: 167-178.

6. Liede A, Malik A I, Aziz Z, Rios L D P, Kwan E, and Narod A S. Contribution of BRCA1 and BRCA2 Mutations to Breast and Ovarian Cancer in Pakistan. Genetics, 2002; 71:595-606.

7. LiedeA, and Narod A S. Hereditary Breast and Ovarian Cancer in Asia: Genetic Epidemiology of BRCA1 and BRCA2. Human Mutation. 2002; 20:413-424.

8. GreeneM H. Genetics of breast cancer. Mayo ClinProc1997; 72: 54-65.

9. Miki Y, Swensen J, Eidens S D, Futreal F P, Harshman K, Tavtigian S, Liu Q, ChocranC, Bennete M L, Ding W, Bell $\mathrm{R}$, Rosenthal J, and Hussey C. A Strong Candidate for the Breast and Ovarian Cancer Susceptibility Gene BRCA1. Science. 1994; 266(5182): 66-71.

10. FutrealA P, Liu Q, and Eidens S D. BRCA1 Mutations in Primary Breast and Ovarian Carcinomas. Science,
1994; 266: 120-122.

11. Ibrahim S S, Hafez E E, and Hashishe $M$ M. Presymptomatic breast cancer in Egypt: role of BRCA1 and BRCA2 tumor suppressor genes mutations dctionete. J ExpClin Cancer Res.2010; 29: 82.

12. Jalkh N, Nassar-Slaba J, Chouery E, SalemN, Uhrchammer N, Golmard L, Stoppa-Lyonnet D,Bignon $Y \mathrm{~J}$, and Megarbane A. Prevalence of BRCA1 and BRCA2 mutations in familial breast cancer patients in Lebanon. Hereditary Cancer in Clinical Practice. 2012; 10:7.

13. Lakhani S R. Molecular genetics of solid tumors: translating research into clinical practice. Molecular Pathology, 2001; 54(5): 281-284.

14. Burke A M, and Goodkin K. Stress and the development of breast cancer: persistence and popular link despite contrary evidence. Cancer, 1997; 79: 1055-1058.

15. Kauff N D, Domchek S M, and Friebel T M. Riskreducing salpingo- oophorectomy for the prevention of BRCA1 and BRCA2 associated breast and gynecologic cancer: A multicenter prospective study. Journal of Clinical Oncology. 2008; 28: 1331-1337.

16. Bhurgri Y, Bhurgri A, Hassan S H, Zaidi S H, Rahim A, Sankaranarayanan $\mathrm{R}$, and Parkin D M. Cancer incidence in Karachi, Pakistan: first results from Karachi Cancer Registry. International Journal of Cancer, 2000; 85: 325-329.

17. Usmani K, Khanum A, Afzal H, and Ahmad N. Breast cancer in Pakistani women. J Environ PatholToxicolOncol1996; 15: 251-253.

18. Shami S A, Qaisar R, and Bittles A H. Consanguinity and adult morbidity in Pakistan. Lancet, 1991; 338: 954-955.

19. Sanger E, Kuenzle C C, Thomas P E, and Hubscher U. DNA finger improvedDNA extraction obtained from small blood samples. Nucleic acid research, 1998; 16: 7738.

20. Chan S, Chen C, Cheung M, and Cheung F. Evaluation of extraction methods from paraffin was embedded 
tissues for PCR amplification of human and viral DNA. J clinc pathology. 2001; 54: 401-403.

21. RahmanN, and Stratton M R. The genetics of breast cancer susceptibility. Annu. Rev. Genet. 1998; 32, 95121.

22. Dufresne SD, Belloni DR, Wells WA, Tsongalis GJ. BRCA1 and BRCA2 mutation screening using Smart Cycler II high-resolution melt curve analysis. Arch
Pathol Lab Med 2006:130:185-7.

23. HussainR, and Bittles AH. Differentials in age at marriage, contraceptive use and fertility in consanguineous marriages in Pakistan. Journal of Biosocial Science 1999; 31,121-138.

24. Castilla H L, Couch J F, and Erods R M. Mutations in the BRCA1 gene in families with early-onset Breast and Ovarian cancer. Nature Genetics, 1994; 8: 387-391.

\section{AUTHOR(S):}

1. DR. MUHAMMAD FIAZ QAMAR

Department of Zoology,

GC University, Lahore- Pakistan

2. MISS FARAH REHMAN

Department of Zoology,

GC University, Lahore- Pakistan

3. MISS SABEEN ILYAS

Department of Zoology,

GC University, Lahore- Pakistan
4. Miss Seher Abbas

Department of Molecular \&Biotechnology,

The Islamia University of Bahawalpur, Pakistan.

Correspondence Address:

Dr. Muhammad Fiaz Qamar

Department of Zoology,

GC University, Lahore- Pakistan

dr.fiazqamar@gcu.edu.pk
Article received on: $03 / 03 / 2013$ Accepted for Publication: $20 / 06 / 2013$ Received after proof reading: 03/12/2013

\section{PREVIOUS RELATED STUDIES}

Mumtaz Begum, Rukhashan Khurshid, Ghazala Ruby, M. Saleem Akhtar, BREAST CANCER; EVALUATION OF CA 15-3 SERUM LEVELS (Original) Prof Med Jour 13(3) 338-340 Jul, Aug, Sep, 2006.

Mukhtar Ahmad, Muhammad Tahir Majeed, Mohammad Jawaid Sabzwari, Muhammad Riaz, Mr. Muhammad Umair BREAST CANCER; ESTIMATION OF TOTAL SERUM SIALIC ACID AND ITS COMPARISON WITH CA 15-3 AS TUMOR MARKER (Original) Prof Med Jour 14(1) 98 -103 Jan, Feb, Mar, 2007.

Muniza Qayyum Malik, Shaheen Rasheed, Rukhshan Khurshid, Asima Malik, Hurriat Afzal, BREAST CANCER; ROLE OF TAMOXIFEN AS SELECTIVE ESTROGEN RECEPTOR MODULATOR IN PREVENTING BONE LOSS, REDUCING SERUM CHOLESTEROLAND ACTIVITY OF LIVER ENZYMES IN PATIENTS WITH DIFFERENTHORMONAL STATES. (Original) Prof Med Jour 16(3) 316-320 Jul, Aug, Sep, 2009.

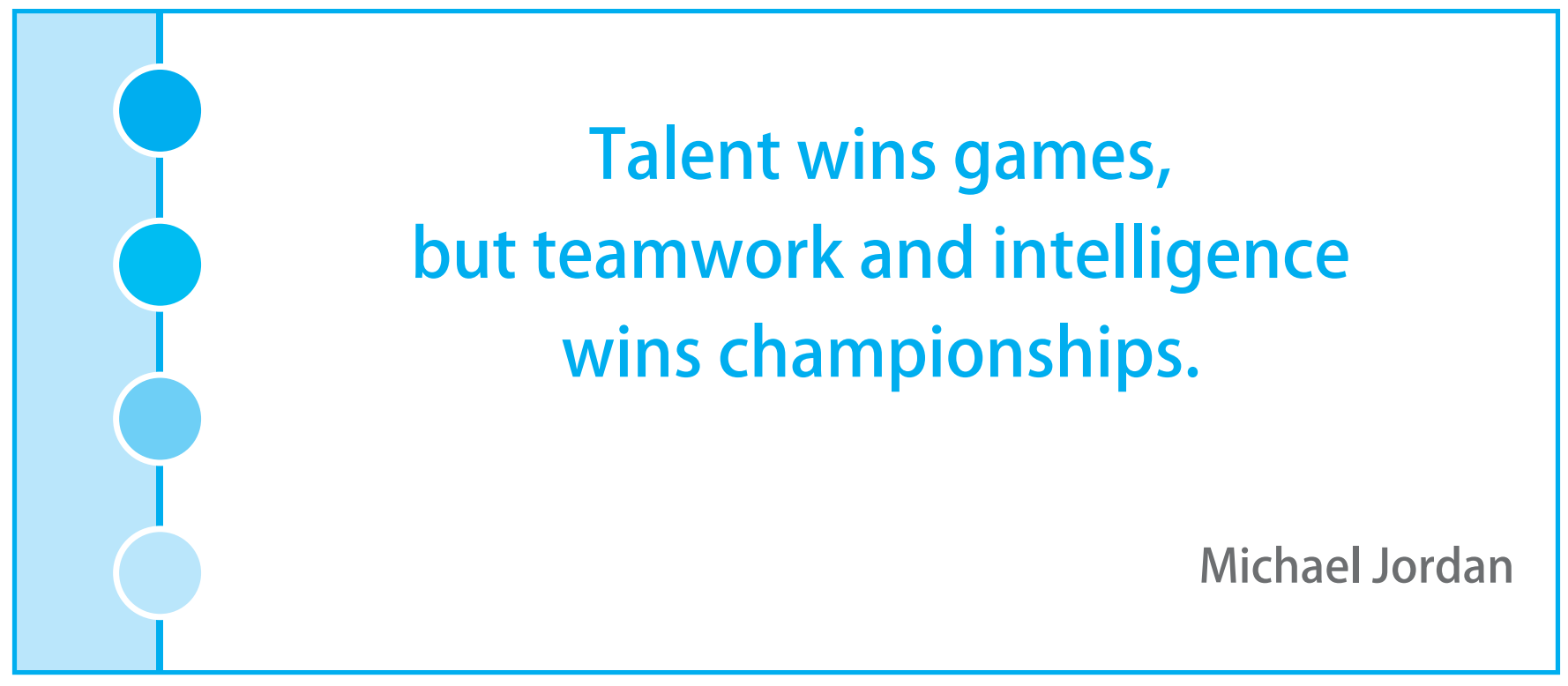

